Note

\title{
Surface-functionalised materials for microplastic removal
}

\author{
O. Rius-Ayra *, A. Biserova-Tahchieva, N. LLorca-Isern \\ CPCM Departament de Ciència dels Materials i Química Física, Facultat de Química, Universitat de Barcelona, Martí i Franquès 1 - 11, 08028 Barcelona, Spain
}

\section{A R T I C L E I N F O}

\section{Keywords:}

Surface functionalisation

Superhydrophobicity

Microplastics

Flotation

Oil/water separation

\begin{abstract}
A B S T R A C T
Microplastic (MP) pollution is a matter of great concern attracting increasing attention due to its adverse effects on the environment. Different technologies and methodologies have been developed to remove these pollutants. Herein, we focus on a promising environmental solution that involves surface modification to change the wettability properties of MPs or solid materials by conferring superhydrophobicity and superoleophilicity to increase the selectivity for MP separation. Both processes can be used to selectively separate MPs because of the changes in the wettable properties of the MP or by changing the oil used in the case of superhydrophobic surfaces. We show two distinct methods based on changing the wettability properties of surfaces that could lead to innovative and environmental applications. We also discuss some of the challenges that need to be overcome.
\end{abstract}

\section{Introduction}

The quality of water is essential to human health, economic development and also the ecosystem. However, during the 21 st century, the environment and, consequently, natural waters have become degraded with human population growth. In fact, more than $80 \%$ of wastewater resulting from human activities such as cities, industry and agriculture are directly discharged into rivers or seas (WWAP (United Nations World Water Assessment Programme), 2017). Thus, it is indispensable to detect emerging pollutants, reduce water pollution and improve wastewater management.

Solid pollutants such as plastics, which are the most prevalent type of debris found in several ecosystems including lakes, rivers, oceans and the atmosphere, are becoming a significant issue around the globe (Xu et al., 2020; Zhang et al., 2020). It has been estimated that 19 to 23 million metric tons of plastic had entered aquatic ecosystems in 2016, with this figure projected to reach up to 53 million metric tons in 2030 (Borrelle et al., 2020). Plastic pollutants can be classified into three different groups according to their size: macroplastics, which have a particle size greater than five millimetres (Barboza et al., 2019); microplastics (MP), which are less than five millimetres in size; and nanoplastics (NP), which are smaller than $1 \mu \mathrm{m}$ (Andrady, 2017; da Costa et al., 2016). Moreover, MPs and NPs present different shapes, such as fibres, spheres or microbeads, and can have different chemical compositions, such as polypropylene (PP), polyethylene (PE), polystyrene (PS), high-density and low density polyethylene (HDPE \& LDPE), poly(methyl methacrylate) (PMMA) or polyvinyl chloride (PVC)
(Fendall and Sewell, 2009; Ziajahromi et al., 2016). Due to their smaller size and ability to penetrate living organisms, these solid pollutants can affect both animal and human health via three pathways: the lungs, the gastrointestinal tract, and the skin (Lehner et al., 2019; Teles et al., 2020). Some of the most important effects are cytotoxicity, metabolic changes, immune responses (Prata et al., 2020; Zhou et al., 2020) and even entering human placentas with different pigments such as iron hydroxide, phthalocyanine or silicates (Ragusa et al., 2021).

Many wastewater treatment processes that are used to remove MPs have been widely reported and reviewed in the literature (Chen et al., 2020; Enfrin et al., 2019; Padervand et al., 2020; Perren et al., 2018; Talvitie et al., 2017), with membranes being the most used to remove MPs (Bayo et al., 2020; Li et al., 2018; Wang et al., 2020b). There are also different methods that have been recently developed to remove MPs. Due to the nature of these processes, they can remove or even accurately select MPs and remove them, such as photocatalytic $\mathrm{Au} @ \mathrm{Ni} @ \mathrm{TiO}_{2}$-based micromotors involving phoretic interactions between the micromotors and the suspended MPs (Wang et al., 2019) or the use of serial faradaic ion concentration polarisation in a microfluidic device that can sort and separate MPs (Davies and Crooks, 2020). A different way of removing MPs is the use of surface-functionalised microbubbles with the inorganic polymer coagulant polyaluminum chloride (PACl) as a bubble modifier (Zhang et al., 2021). In fact, coagulative colloidal gas aphrons (CCGAs) modified with PACl have been used to remove a mixture of MPs that are $\sim 5 \mu \mathrm{m}$ in diameter (PMMA and PS) and dissolved organic matter.

Herein, we review and discuss two main innovative trends based on

\footnotetext{
* Corresponding author.

E-mail address: oriolriusayra@ub.edu (O. Rius-Ayra).
} 
changes in wettability. The surface functionalisation of MPs or solid surfaces to change the surface free energy of the systems is the major characteristic of these processes to remove MPs from water. Moreover, as discussed later, after changing the wettability properties of MPs to confer a greater hydrophilic character or after conferring superhydrophobicity/superoleophilicity to solid surfaces, MPs can be easily removed. The main objective of the following section is to show the most recent results of MP surface functionalisation methods as well as the use of superhydrophobic materials with oil/water separation abilities as an innovative strategy to remove MPs from water.

\section{Wettability phenomena}

A system is formed by a continuous phase (water) that can contain solid pollutants like MPs, with air present at the interface. The whole system is defined by the surface free energy $(\gamma)$ between the three different phases, which promotes a contact angle $\left(\theta_{0}\right)$ between the solid surface (S), water (W) and air (A). This relationship is defined by the well-known Young's equation (Eq. (1)):

$\cos \theta_{\mathrm{o}}=\gamma_{\mathrm{SA}}-\gamma_{\mathrm{SW}} / \gamma_{\mathrm{WA}}$

As the contact angle changes, different surfaces can be achieved with distinct wetting properties such as superhydrophilicity $\left(\theta_{0}<5^{\circ}\right)$, hydrophilicity $\left(\theta_{0}<90^{\circ}\right)$, hydrophobicity $\left(90^{\circ}<\theta_{0}<150^{\circ}\right)$ and superhydrophobicity $\left(\theta_{\mathrm{o}} \geq 150^{\circ}\right)$ (Nuraje et al., 2013; Oberli et al., 2014). In addition, if in the previously described system, an immiscible organic phase such as oil (O) is also present and a flat surface is assumed, the underwater oil contact angle can be calculated with the Bartell-Osterhof equation as follows (Bartell and Osterhof, 1927) (Eq. (2)):

$\cos \theta_{\mathrm{OW}}=\gamma_{\mathrm{OA}} \cos \theta_{\mathrm{o}}-\gamma_{\mathrm{WA}} \cos \theta_{\mathrm{w}} / \gamma_{\mathrm{OW}}$

where $\theta_{\mathrm{ow}}, \theta_{\mathrm{w}}$, and $\theta_{\mathrm{o}}$ are the underwater contact angle (UWOCA), the static water contact angle (WCA), and the static oil contact angle (OCA), respectively, while $\gamma_{o a}, \gamma_{w a}$, and $\gamma_{o w}$ represent the surface free energy of oil-air, water-air, and oil-water, respectively.

Generally speaking, the surface free energy of solid polymers and, consequently, MPs at $20^{\circ} \mathrm{C}$ ranges from $30.1 \mathrm{mN} / \mathrm{m}$ for PP, $35.7 \mathrm{mN} / \mathrm{m}$ for PE, $40.7 \mathrm{mN} / \mathrm{m}$ for PS, $41.4 \mathrm{mN} / \mathrm{m}$ for PMMA to $41.5 \mathrm{mN} / \mathrm{m}$ for PVC, while the surface free energy for water is $72.8 \mathrm{mN} / \mathrm{m}$. Therefore, polymers exhibit a WCA close to $90^{\circ}$, showing hydrophobicity due to their low surface free energy, that is, they are not completely wet. As a consequence, it is considerably difficult to remove MPs using traditional methods. It is important to take into account that the WCA depends on the surface free energy of the materials as well as on the surface roughness of each polymer. Thus, the WCA only indicates the roughness of the polymers. It is therefore more interesting to determine the surface free energy of the polymers as it is an intrinsic property of each material.

Another way to modify wettability at the surfaces is to change the phases present in the previously described system (water-air-solid) and add another solid with superwettable properties. To obtain a solid surface with superwettable properties, it is necessary to build a system involving a microstructure with nanoscale features, leading to a hierarchical structure. This structure has to then be functionalised with substances that decreases the surface free energy of the whole system such as fluorocarbons (Huang et al., 2015; Saleema et al., 2010; Song et al., 2012; Wu et al., 2012), silanes (Song et al., 2019), fatty acids (Zhang et al., 2018) or polydimethylsiloxane (PDMS) (Davis et al., 2018), where the energy decreases in the following order of $\mathrm{CH}_{2}>\mathrm{CH}_{3}$ $>\mathrm{CF}_{2}>\mathrm{CF}_{2} \mathrm{H}>\mathrm{CF}_{3}$, producing an extremely high WCA (Alonso Frank et al., 2017). Superhydrophobic surfaces are defined by a WCA $>150^{\circ}$, sliding angles (SA) $<10^{\circ}$ and contact angle hysteresis $(\mathrm{CAH})<10^{\circ}$, which leads to low adhesion and self-cleaning properties (Bhushan and Jung, 2010; Gao and McCarthy, 2006). Surfaces are usually described as superhydrophobic in solid-water-air systems, but when air is replaced with another immiscible fluid such as oil, the surface also presents superoleophilic properties, with an OCA close to $0^{\circ}$. This means that while the surface repels water, the oil phase is able to spread throughout the whole surface before being sorbed (Liu et al., 2017; Su et al., 2016). Superhydrophobic materials have been revealed to be an innovative strategy in the removal of pollutants such as oil-in-water emulsions (Fu et al., 2020; Wang et al., 2015), as well as in water purification (Miao et al., 2020b; Yang et al., 2019) or as a corrosion barrier in marine environments (Miao et al., 2020a; Montemor, 2014; Vazirinasab et al., 2018; Vengatesh and Kulandainathan, 2015). However, the use of superhydrophobic materials in the removal of solid pollutants such as MPs has to be further characterised to determine the main surface processes that lead to the removal.

\section{Surface modification processes}

In this section, two different methods based on the surface modification of the MP or solid surfaces will be discussed. The challenge of these methods is to change the surface chemistry of MPs using surface modifiers such as $\mathrm{Fe}_{3} \mathrm{O}_{4}$ or carboxylate groups (Fig. 1a) or by using superhydrophobic/superoleophilic solid surfaces (Fig. 1b) and conferring different wettable properties on them.

Due to the change in the surface chemistry of the solid materials or MPs, new interactions appear between the solid surface, which can be the MPs themselves or the superhydrophobic surface, and the surrounding media, which is the water or oil. This improves the ability to remove MPs from water.

\subsection{Functionalised MP surfaces}

The surface of MPs can be modified with different substances to confer hydrophilicity and increase their permeability to water. This increases the ability to remove MPs from water due to the conferred affinity of the solid pollutants for water after surface treatment. As the surface of solid pollutants like MPs is changed after functionalisation, the contact angle also changes to indicate hydrophilicity. For MPs whose surfaces are modified with hydrophilic substances such as hydroxyls $\left(\mathrm{OH}^{-}\right)$, carboxylates $\left(\mathrm{COO}^{-}\right)$, oxides $\left(\mathrm{O}^{2-}\right)$ or amides $\left(\mathrm{CO}-\mathrm{NH}_{2}\right)$, the WCA between the solid surface and the water phase decreases, revealing a higher affinity for water compared to MPs without surface functionalisation.

A previous study fabricated magnetite $\left(\mathrm{Fe}_{3} \mathrm{O}_{4}\right)$ nanoparticles on the surface of non-PVC (PS and PMMA among others) and PVC MPs via the coprecipitation method in order to facilitate the flotation of PVC before their separation (Wang et al., 2021). This process led to a homogeneous $\mathrm{Fe}_{3} \mathrm{O}_{4}$ nanoparticle coating of the non-PVC surface. Consequently, their WCA decreased nearly $30^{\circ}$, revealing a higher affinity of the MPs for water (Fig. 2). By contrast, $\mathrm{Fe}_{3} \mathrm{O}_{4}$ nanoparticles were barely formed on the PVC surface and the WCA changed slightly $\left(\sim 7^{\circ}\right)$. The presence of $-\mathrm{OH}$ groups with $\mathrm{Fe}_{3} \mathrm{O}_{4}$ decreased the WCA, with the hydrophilic properties facilitating the non-destructive hydrophilisation of the polymers. The difference in surface chemistry between the MPs was used to selectively separate PVC from MP mixtures (non-PVC and PVC MP). In fact, the wettability of the modified surfaces caused inverse flotation of the MPs, facilitating the flotation of PVC that allowed its separation from the mixtures of MPs. The whole process showed a removal efficiency of $100 \%$. To avoid secondary pollution, $\mathrm{Fe}_{3} \mathrm{O}_{4}$ on the MP surface can be removed by simple acid pickling.

Another study functionalised the surfaces of different polymers like acrylonitrile butadiene styrene (ABS) and non-ABS polymers (PS, PMMA or PVC) with hypochlorite $\left(\mathrm{ClO}^{-}\right)$to promote oxygen functionalities by increasing the number of carboxyl and hydroxyl functional groups (Wang et al., 2020a). The surface functionalisation reduced the WCA, indicating a hydrophilic nature of the modified MP surfaces. The WCA of the ABS MPs showed a larger decrease $\left(24.7^{\circ}\right)$ than those of the other polymers. In fact, the hydrophilic properties of the ABS MPs after functionalisation conferred selectivity to the separation of MP mixtures, 

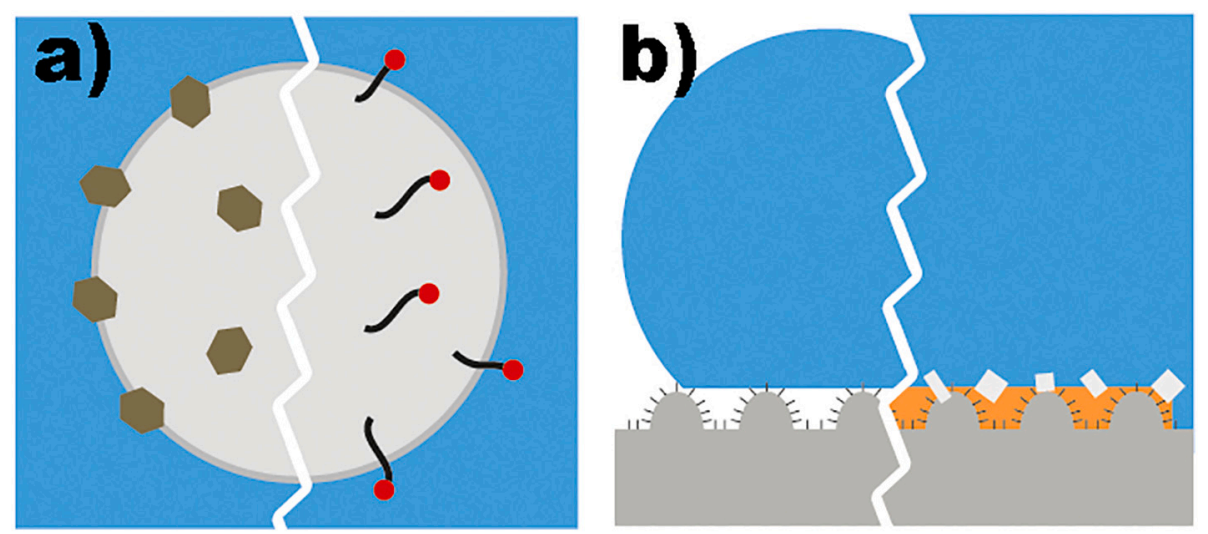

Fig. 1. The two different surface modification processes discussed: (a) surface modification of MPs with hydrophilic compounds such as $\mathrm{Fe}_{3} \mathrm{O}_{4}$ (left) and a carboxylate group (right); and (b) superhydrophobic surface with superoleophilic properties containing MPs at the oil/water interface.

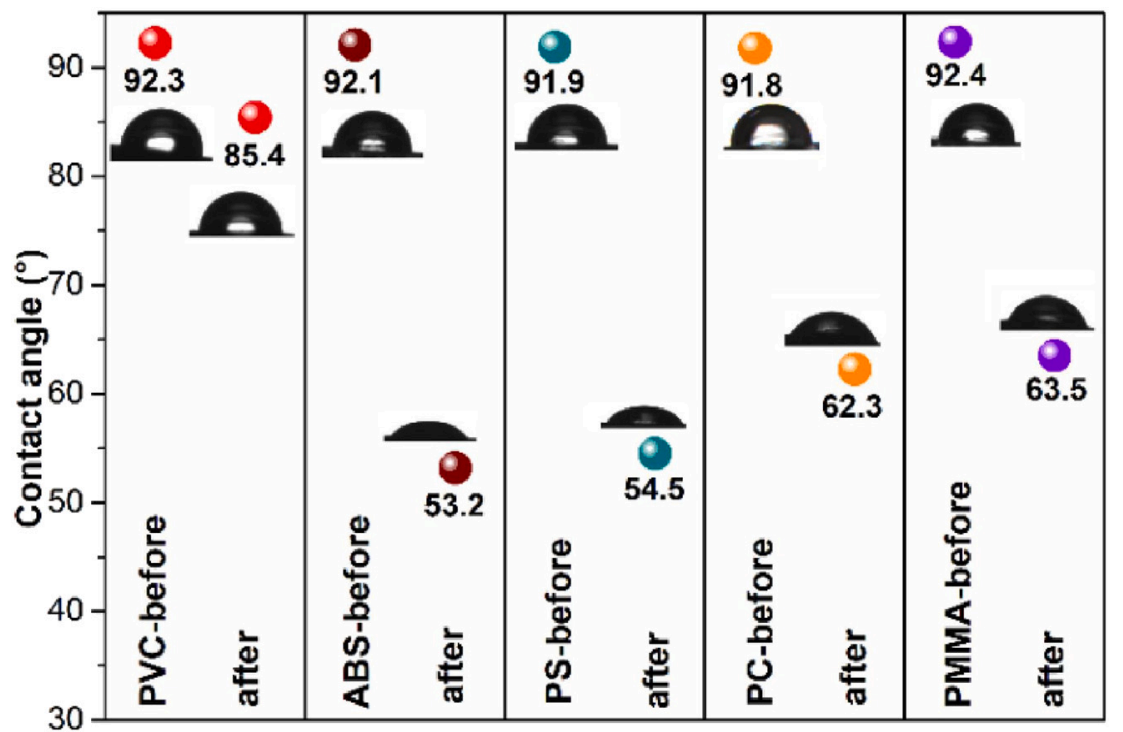

Fig. 2. Water contact angles of different MPs before and after surface functionalisation, revealing hydrophobicity of the PVC MPs and hydrophilicity of the non-PVC MPs.

Reprinted with permission from Elsevier (Wang et al., 2021).

resulting in a sinking behaviour in flotation. As.

Fig. 3, the MPs presented two distinct behaviours depending on the surface functionalisation during the flotation process when three different phases (solid, air and water) were present. Before surface functionalisation, all types of MPs floated during the process due to their high WCA and hydrophobic properties. Once the ABS MPs were functionalised, their wetting properties changed to a hydrophilic state and completely sank, in contrast to the non-ABS polymers that floated due to their hydrophobic properties. This difference in flotation showed high selectivity for the ABS polymers. Thus, the separation of ABS MPs from the MP mixtures had an efficiency of $99.8 \%$. There are also promising methods based on functionalised surfaces such as the use of $\mathrm{TiO}_{2}$ nanoparticles to coat polypropylene MPs in order to study the acceleration of the photocatalytic reaction of the aging process of MPs (Luo et al., 2021).

In summary, after modifying the surface of MPs with compounds like $\mathrm{Fe}_{3} \mathrm{O}_{4}, \mathrm{OH}^{-}$or $\mathrm{COO}^{-}$, the wettability properties change from a hydrophobic state to a hydrophilic one that decreases the WCA, indicating high permeability of the MPs to the water phase. Moreover, this modification allows to selectively functionalise the MP surface, which leads to a more specific separation of different types of MPs. Finally, the flotation process enables the effective separation of the different MPs according to their affinity for water, separating the modified hydrophilic MPs from those that have not been modified.

\subsection{Functionalised solid surfaces}

Superhydrophobic materials also have innovative applications in the removal of pollutants. In fact, we recently found that these extraordinary materials that mimic materials found in nature, such as Nelumbo nucifera (known as lotus leaf), can also be used to remove solid pollutants like MP. For the first time, we previously reported a superhydrophobic iron powder used to capture HDPE-MP fibres (Rius-Ayra et al., 2020). To obtain this powder, we used high-energy ball milling to decrease the size of the iron particles to close to $50 \mu \mathrm{m}$. After that, liquid phase deposition of lauric acid was used to modify the surface free energy of the iron powder, which produced a superhydrophobic material $\left(\mathrm{WCA}=154^{\circ}\right)$ with superoleophilicity $\left(\mathrm{OCA}=0^{\circ}\right)$. Taking advantage of its superwettability and underwater superoleophilic properties, the powder was used to capture HDPE-MPs and remove them from aqueous solutions at different concentrations ranging from $0.2 \mathrm{MP} / \mathrm{L}$ to $2 \mathrm{MP} / \mathrm{L}$.

To remove MPs with the superhydrophobic iron powder, the system consisted of two different phases: water and an immiscible phase of oil such as hexane. First, during the stirring of the water phase containing 

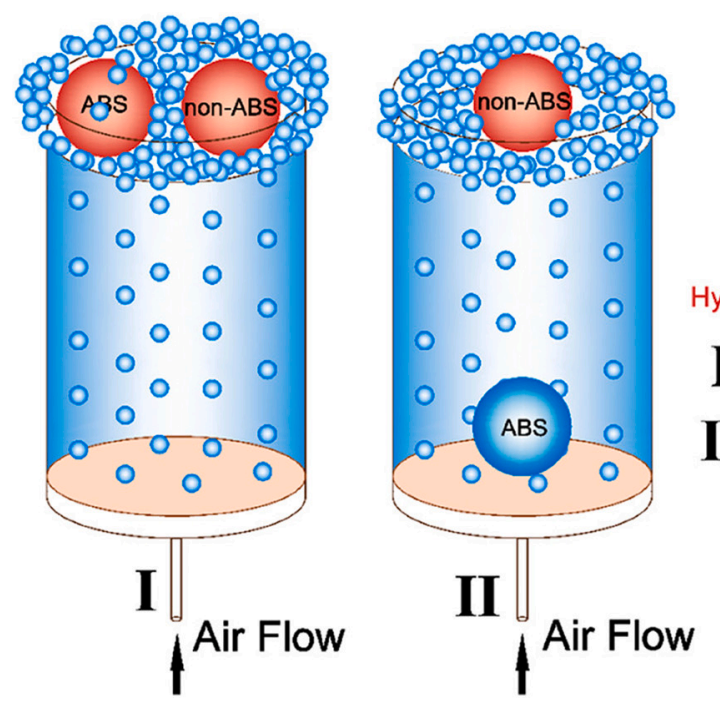

Fig. 3. Flotation of ABS MPs before and after surface functionalisation with hypochlorite that conferred hydrophilic properties.

Reprinted with permission from ACS Appl. Mater. Interfaces (Wang et al., 2020a).

the MPs, the solid pollutants were located at the bottom part of the vortex (Fig. 4a). After hexane was poured into the water, two separated phases were achieved (Fig. 4b). Due to the intrinsic hydrophobic character of the HDPE-MPs, they were displaced from the aqueous phase to the organic phase. The superhydrophobic iron particles were then added to the vortex to capture the MPs (Fig. 4c-e). Finally, the iron particles containing the MPs were removed with a permanent magnet and the water was decanted (Fig. 4f).

An increasingly important issue in the removal process is the fragmentation of MPs into NPs, which increases the difficulty in removing these pollutants. Therefore, methods that do not break down the polymers should be used. When using the powdered iron to remove MPs, the size and morphology of the MPs were measured before and after the removal process. Before the capture process, the MPs were $795 \pm 318$ $\mu \mathrm{m}$ in length and $487 \pm 147 \mu \mathrm{m}$ in width. After the capture, the size decreased by $30 \%$ ( $553 \pm 174 \mu \mathrm{m}$ in length and $343 \pm 134 \mu \mathrm{m}$ in width). Regarding the morphology, the MPs changed from having an irregular shape to a more rounded one due to the stirring process. These results revealed that during the stirring process in the oil phase, the superhydrophobic iron particles could freely adapt to the different morphologies of the MPs, capturing MPs with efficiencies of $100 \%$ at low MP concentrations or $90 \%$ at high MP concentrations. Finally, to remove the MPs and reuse the powdered iron, the mixture was washed with ethanol to remove the oil. A small quantity of water was added under sonication to detach the MPs and under a constant magnetic field, the water containing the detached MPs was decanted.

As MPs are found in natural waters and usually in marine environments, it is important to take into account the corrosion of superhydrophobic materials. Therefore, the ability of these surfaces to remove MPs from $3.5 \mathrm{wt} \% \mathrm{NaCl}$ aqueous solution was studied. First, a superhydrophobic/superoleophilic (WCA $=154^{\circ}$ and OCA $=0^{\circ}$ ) surface was obtained by combining anodisation with the liquid phase deposition of lauric acid (Rius-Ayra and Llorca-Isern, 2021). Polarisation curves of the superhydrophobic surface showed excellent resistance to corrosion.

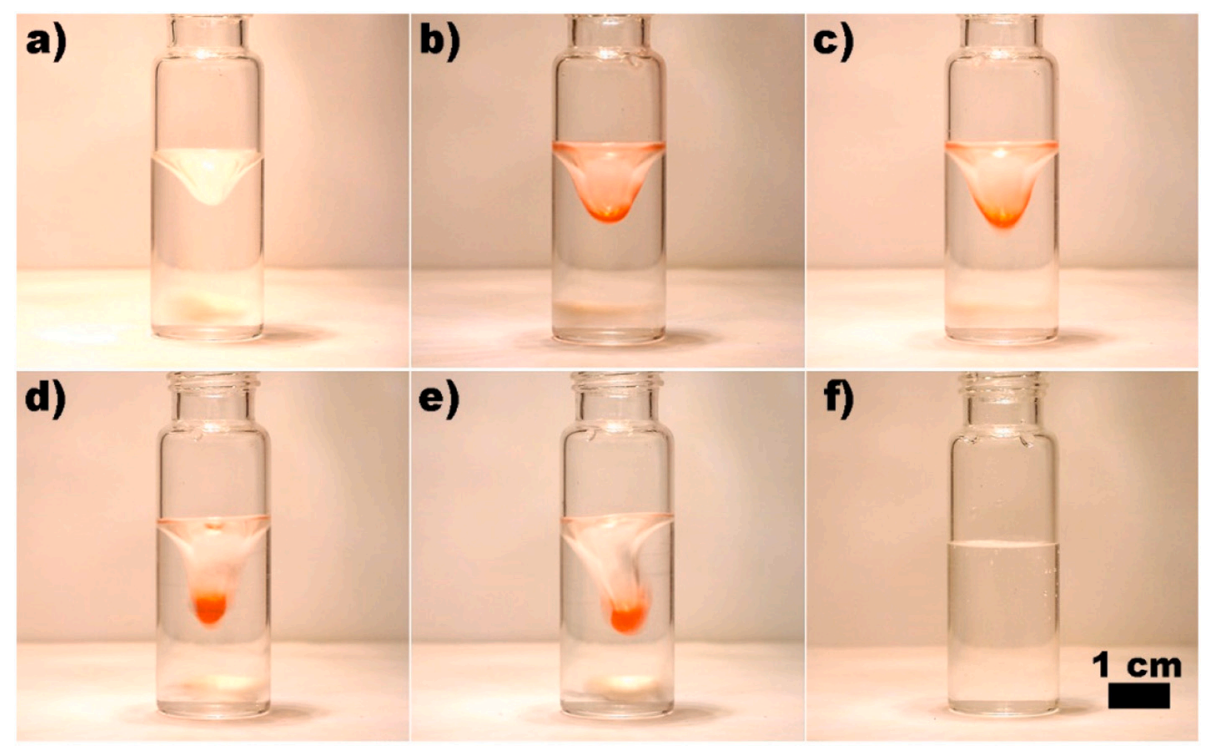

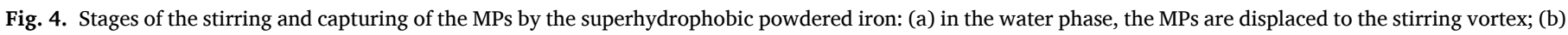
hexane is added to the system; (c-e) superhydrophobic powdered iron is added to the vortex; and (f) water without the presence of MPs or hexane. Reprinted with permission from ACS Appl. Mater. Interfaces (Rius-Ayra et al., 2020). 
Trichloroethylene was used to move PP MPs (size $=262 \pm 4 \mu \mathrm{m}$ ) from the aqueous phase (concentration $=53 \pm 7 \mathrm{MP} / \mathrm{mL}$ ) to the oil phase. Initially, $150 \mu \mathrm{L}$ of trichloroethylene were poured until the MPs were moved to the organic phase, showing hydrophobicity and oleophilicity. The superhydrophobic surface was then moved towards the trichloroethylene droplets containing the MPs until the MPs were no longer observable and completely removed. This method was able to capture $30 \pm 4 \mathrm{MP} / \mathrm{mL}$ during $12 \mathrm{~s}$ (Fig. 5a). The process was repeated for a second and third time, removing $18 \pm 2 \mathrm{MP} / \mathrm{mL}$ over $7 \mathrm{~s}$ (Fig. $5 \mathrm{~b}$ ) and 5 $\pm 1 \mathrm{MP} / \mathrm{mL}$ over $3 \mathrm{~s}$, respectively, without any MP remaining in the oil droplet (Fig. 5c).

As commented before, the particle size before and after the removal process is important to measure in order to determine whether the polymeric particles break down. After the capture with the anodised superhydrophobic surface, the particle size of the MPs remained unchanged, revealing an average size of $264 \pm 3 \mu \mathrm{m}$. Interestingly, the MP concentration decreased after each removal step, while the area of the surface used to capture the MPs increased from $0.94 \mathrm{~cm}^{2}$ in the first removal step to $1.7 \mathrm{~cm}^{2}$ in the second step to $2.8 \mathrm{~cm}^{2}$ in the third step. This behaviour could be explained as follows. During the first step, the oil droplet containing the MPs was adsorbed by the surface due to its wettability properties. Once the surface was saturated with the oil, it could not remove any more MP. Consequently, the MPs were found at the lower part of the surface. In the second step, as the MP concentration had decreased during the first removal step, more surface was required to adsorb the oil and the remaining MPs. Due to their lower concentration, the MPs occupied the whole immersed surface. Finally, in the third step, the MPs were also found at the lower part of the surface. As described before, the oil had spread throughout the surface, carrying the small amount of the remaining MPs. Therefore, these remaining MPs were at the lower part of the surface. The whole removal process showed an efficiency higher than $99 \%$.

Superhydrophobic surfaces also promote antifouling due to their self-cleaning properties (water contact angle $>150^{\circ}$ and contact angle hysteresis $<10^{\circ}$ ) (Bhushan and Jung, 2011). Once the organic phase is removed, the MPs are easily removed from the surface. Thus, these surfaces prevent the fouling of MPs and increase the long-term removal stability.

In the case of superhydrophobic surfaces used to remove MPs, the main mechanism is also based on the wettability properties of the MPs and the surrounding phase. However, in contrast to the surface-modified MPs that present hydrophilicity, the MPs in this case are hydrophobic and have a high affinity for organic solvents (oils) as well as oleophilicity. Superhydrophobic surfaces also present superoleophilicity, allowing immiscible organic solvents to be adsorbed throughout their whole surface. The MPs migrate from the aqueous phase to the organic phase given their high affinity for organic solvents. Thus, the superhydrophobic surface adsorbs and removes the oil containing the MPs.

Taking into account the properties of both MPs and solid materials that have undergone surface functionalisation, both of them could be used at the same time to selectively remove MPs and carefully separate them for future industrial purposes or even recycle them. Herein, we propose a possible removal method that could be used to remove MPs from natural water using the abovementioned processes with different steps. First, a mixture of different types of MPs (such as PVC, ABS, PP and $\mathrm{PE}$ ) would be treated using $\mathrm{ClO}^{-}$surface functionalisation in order to sediment the non-ABS MPs and promote the floating of ABS MPs. In this first step, ABS MPs would be easily separated from the other MPs. Second, the remaining mixture (PVC, PP and PE) would be modified using $\mathrm{Fe}_{3} \mathrm{O}_{4}$ to change the surface of the MPs and also their wettability properties. As PVC cannot be modified, it would float while the remaining MPs would sediment and be recovered from the bottom of the separation container. During the third and fourth steps of this proposed process, the remaining MPs would be separated using superhydrophobic materials and two different types of oils. In the third step, PE MPs would be captured using the stirring method of superhydrophobic iron particles with hexane. Finally, the PP MPs would be removed using trichloroethylene as the oil phase and moving the superhydrophobic surface towards the trichloroethylene phase containing the MPs to completely remove them.

\section{Future challenges}

The environmental concern and interest from the scientific community about the prevention of man-made pollutants and their effects on water and soil will only increase in the near future. Scientists are continuously facing challenges and are focused on researching environmental issues such as the quantification of small-sized MPs or their effects on animal and human health.

Herein, we showed that MPs or solid materials that have undergone surface modification show promise in the treatment of pollutants. MPs can be functionalised with different reactants such as $\mathrm{Fe}_{3} \mathrm{O}_{4}$ in the case of PVC (Wang et al., 2021) and hypochlorite in the cases of PMMA and PS (Wang et al., 2020a), resulting in hydrophilic properties. Additionally, functionalisation of solid surfaces with lauric acid confers superhydrophobic properties, allowing them to remove HDPE (Rius-Ayra et al., 2020) and PP (Rius-Ayra and Llorca-Isern, 2021).

As shown previously, the surface functionalisation of MPs increases the removal selectivity for different types of MPs in a mixture of these solid pollutants. Thus, this characteristic should be taken into account as it opens up a wide range of removal processes, such as the separation of MPs depending on their nature and chemical composition. In fact, as it has been shown that the chemical composition of MPs affects the functionalisation of their surface, it is important to also consider copolymer MPs with different chemical compositions. Moreover, biofilm formation throughout the MP surface has to be considered as it might decrease the ability to functionalise their surface. Although some processes, such as those using membranes, can remove MPs with high
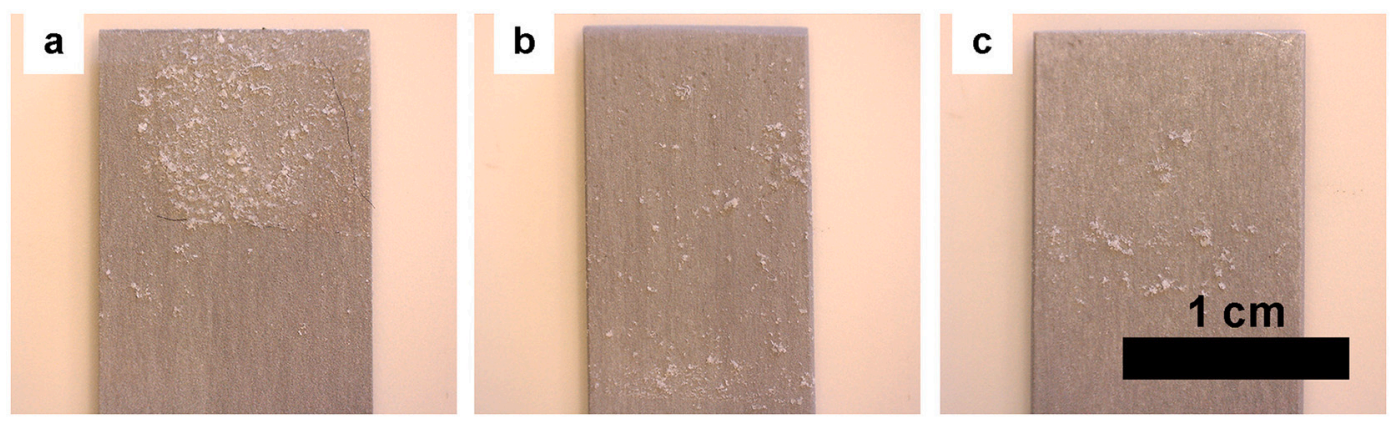

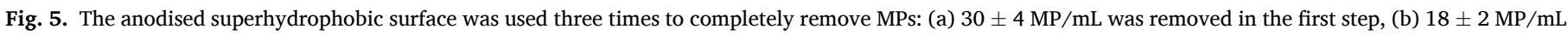
was removed in the second stage, and finally (c) $5 \pm 1 \mathrm{MP} / \mathrm{mL}$ was removed in the third step.

Reprinted with permission from Elsevier (Rius-Ayra and Llorca-Isern, 2021). 
efficiencies and are easily scalable to wastewater treatment plants, they currently lack selectivity against the many different chemical compositions and sizes of MPs.

Regarding superhydrophobic surfaces, different MPs require different oils to move the MPs from the aqueous phase to the organic one. This behaviour could be considered when attempting to selectively remove MPs using superhydrophobic surfaces. Apart from the selectivity, the ability to remove solid pollutants, such as MPs, through the use of immiscible pollutants still needs appropriate and efficient technology. Therefore, further research is needed to select the most sustainable oil to remove MPs and prevent the addition of unnecessary pollutants during MP removal or at least an efficient method to remove them. Additionally, the most used wastewater treatments like the application of membranes also lead to fouling of organisms and even MPs throughout the whole surfaces. This decreases the long-term efficiency of the system and halts the process so that the organic or inorganic matter accumulated throughout the whole surface can be removed. This issue could be addressed by using superhydrophobic materials, given their extremely low contact angles and self-cleaning properties that allow pollutants to be easily removed from the surface.

Moreover, one of the most important challenges is related to the MP size. Due to the wide range of sources and their fragmented aspect, it is extremely difficult managing their high concentrations in water environments most of the time. However, the new approaches described here involving surface modification could be used to functionalise NPs or apply superhydrophobic systems in the removal of NPs from wastewater.

\section{Conclusions}

Among the wide variety of methods and processes used to remove MPs, MPs with functionalised surfaces as well as superhydrophobic surfaces should be taken into account. These methods promote the selectivity of MP removal, undoubtedly improving their future uses and decreasing residues in water treatment plants. In fact, MP surface functionalisation (with $\mathrm{ClO}^{-}$or $\mathrm{Fe}_{3} \mathrm{O}_{4}$ ) confers hydrophilic properties to the solid pollutants, increasing selectivity in the separation process. While selectivity when using superhydrophobic surfaces depends on the oil used, MPs can also be separated by their chemical composition. The key challenge for the future is based on the production of safer products and processes to remove solid pollutants. Alongside this, it is necessary to carry out fundamental research to better comprehend how to remove MPs and determine the mechanisms involved. To be successful, the strategy should involve environmentally friendly reactions, products and processes, and comply with future regulations.

\section{CRediT authorship contribution statement}

O. Rius-Ayra: Conceptualization, Investigation, Writing - Original Draft, Writing - Review Editing, Visualization. A. Biserova-Tahchieva: Investigation, Writing - Original Draft, Writing - Review Editing. N. Llorca-Isern: Writing - Review Editing, Supervision.

\section{Declaration of competing interest}

The authors declare that they have no known competing financial interests or personal relationships that could have appeared to influence the work reported in this paper.

\section{References}

Alonso Frank, M., Meltzer, C., Braunschweig, B., Peukert, W., Boccaccini, A.R., Virtanen, S., 2017. Functionalization of steel surfaces with organic acids: influence on wetting and corrosion behavior. Appl. Surf. Sci. 404, 326-333. https://doi.org/ 10.1016/j.apsusc.2017.01.199.

Andrady, A.L., 2017. The plastic in microplastics: a review. Mar. Pollut. Bull. 119, 12-22. https://doi.org/10.1016/j.marpolbul.2017.01.082.
Barboza, L.G.A., Cózar, A., Gimenez, B.C.G., Barros, T.L., Kershaw, P.J., Guilhermino, L., 2019. Macroplastics pollution in the marine environment, in: World Seas: An Environmental Evaluation. Elsevier, pp. 305-328. doi:https://doi.org/10.10 16/B978-0-12-805052-1.00019-X.

Bartell, F.E., Osterhof, H.J., 1927. Determination of the wettability of a solid by a liquid: relation of adhesion tension to stability of color varnish and lacquer systems. Ind. Eng. Chem. 19, 1277-1280. https://doi.org/10.1021/ie50215a026.

Bayo, J., López-Castellanos, J., Olmos, S., 2020. Membrane bioreactor and rapid sand filtration for the removal of microplastics in an urban wastewater treatment plant. Mar. Pollut. Bull. 156, 111211. https://doi.org/10.1016/j.marpolbul.2020.111211.

Bhushan, B., Jung, Y.C., 2010. Natural and biomimetic artificial surfaces for superhydrophobicity, self-cleaning, low adhesion, and drag reduction. Prog. Mater. Sci. 56, 1-108. https://doi.org/10.1016/j.pmatsci.2010.04.003.

Bhushan, B., Jung, Y.C., 2011. Natural and biomimetic artificial surfaces for superhydrophobicity, self-cleaning, low adhesion, and drag reduction. Prog. Mater. Sci. 56, 1-108. https://doi.org/10.1016/j.pmatsci.2010.04.003.

Borrelle, S.B., Ringma, J., Law, K.L., Monnahan, C.C., Lebreton, L., McGivern, A., Murphy, E., Jambeck, J., Leonard, G.H., Hilleary, M.A., Eriksen, M., Possingham, H. P., De Frond, H., Gerber, L.R., Polidoro, B., Tahir, A., Bernard, M., Mallos, N., Barnes, M., Rochman, C.M., 2020. Predicted growth in plastic waste exceeds efforts to mitigate plastic pollution. Science (80-. ). 369, 1515-1518. doi:https://doi.org/1 $0.1126 /$ science.aba3656.

Chen, Z., Liu, J., Chen, C., Huang, Z., 2020. Sedimentation of nanoplastics from water with $\mathrm{Ca} / \mathrm{Al}$ dual flocculants: characterization, interface reaction, effects of $\mathrm{pH}$ and ion ratios. Chemosphere 252, 126450. https://doi.org/10.1016/j. chemosphere.2020.126450.

da Costa, J.P., Santos, P.S.M., Duarte, A.C., Rocha-Santos, T., 2016. (Nano)plastics in the environment - sources, fates and effects. Sci. Total Environ. 566-567, 15-26. https://doi.org/10.1016/j.scitotenv.2016.05.041.

Davies, C.D., Crooks, R.M., 2020. Focusing, sorting, and separating microplastics by serial faradaic ion concentration polarization. Chem. Sci. 11, 5547-5558. https:// doi.org/10.1039/D0SC01931C.

Davis, A., Surdo, S., Caputo, G., Bayer, I.S., Athanassiou, A., 2018. Environmentally benign production of stretchable and robust superhydrophobic silicone monoliths. ACS Appl. Mater. Interfaces 10, 2907-2917. https://doi.org/10.1021/ acsami.7b15088.

Enfrin, M., Dumée, L.F., Lee, J., 2019. Nano/microplastics in water and wastewater treatment processes - origin, impact and potential solutions. Water Res. 161, 621-638. https://doi.org/10.1016/j.watres.2019.06.049.

Fendall, L.S., Sewell, M.A., 2009. Contributing to marine pollution by washing your face: microplastics in facial cleansers. Mar. Pollut. Bull. 58, 1225-1228. https://doi.org/ 10.1016/j.marpolbul.2009.04.025.

Fu, C., Gu, L., Zeng, Z., Xue, Q., 2020. One-step transformation of metal meshes to robust superhydrophobic and superoleophilic meshes for highly efficient oil spill cleanup and oil/water separation. ACS Appl. Mater. Interfaces 12, 1850-1857. https://doi. org/10.1021/acsami.9b17052.

Gao, L., McCarthy, T.J., 2006. Contact angle hysteresis explained. Langmuir 22, 6234-6237. https://doi.org/10.1021/la060254j.

Huang, Y., Sarkar, D.K., Grant Chen, X., 2015. Superhydrophobic aluminum alloy surfaces prepared by chemical etching process and their corrosion resistance properties. Appl. Surf. Sci. 356, 1012-1024. https://doi.org/10.1016/j. apsusc.2015.08.166.

Lehner, R., Weder, C., Petri-Fink, A., Rothen-Rutishauser, B., 2019. Emergence of nanoplastic in the environment and possible impact on human health. Environ. Sci. Technol. 53, 1748-1765. https://doi.org/10.1021/acs.est.8b05512.

Li, L., Xu, G., Yu, H., Xing, J., 2018. Dynamic membrane for micro-particle removal in wastewater treatment: performance and influencing factors. Sci. Total Environ. 627, 332-340. https://doi.org/10.1016/j.scitotenv.2018.01.239.

Liu, M., Wang, S., Jiang, L., 2017. Nature-inspired superwettability systems. Nat. Rev. Mater. 2, 17036. https://doi.org/10.1038/natrevmats.2017.36.

Luo, H., Xiang, Y., Li, Y., Zhao, Y., Pan, X., 2021. Photocatalytic aging process of NanoTiO2 coated polypropylene microplastics: combining atomic force microscopy and infrared spectroscopy (AFM-IR) for nanoscale chemical characterization. J. Hazard. Mater. 404, 124159. https://doi.org/10.1016/j.jhazmat.2020.124159.

Miao, X., Zhu, C., Ren, G., Sun, X., Li, Y., 2020b. Rapid, large-scale preparation of nonwetting bismuth oxybromide surface and its practical outdoor applications for the water purification. Appl. Surf. Sci. 515, 146099. https://doi.org/10.1016/j. apsusc.2020.146099.

Miao, Y., Zhang, D., Cao, N., Yang, L., Ju, H., Boukherroub, R., Lin, X., Li, H., Jin, Y., 2020a. Mussel-inspired superhydrophobic surfaces on 316L stainless steel with enhanced corrosion resistance. Metall. Mater. Trans. A 51, 909-919. https://doi.org/ 10.1007/s11661-019-05573-7.

Montemor, M.F., 2014. Functional and smart coatings for corrosion protection: a review of recent advances. Surf. Coat. Technol. 258, 17-37. https://doi.org/10.1016/j. surfcoat.2014.06.031.

Nuraje, N., Khan, W.S., Lei, Y., Ceylan, M., Asmatulu, R., 2013. Superhydrophobic electrospun nanofibers. J. Mater. Chem. A 1, 1929-1946. https://doi.org/10.1039/ c2ta00189f.

Oberli, L., Caruso, D., Hall, C., Fabretto, M., Murphy, P.J., Evans, D., 2014. Condensation and freezing of droplets on superhydrophobic surfaces. Adv. Colloid Interf. Sci. 210, 47-57. https://doi.org/10.1016/j.cis.2013.10.018.

Padervand, M., Lichtfouse, E., Robert, D., Wang, C., 2020. Removal of microplastics from the environment. A review. Environ. Chem. Lett. 18, 807-828. https://doi.org/ 10.1007/s10311-020-00983-1. 
Perren, W., Wojtasik, A., Cai, Q., 2018. Removal of microbeads from wastewater using electrocoagulation. ACS Omega 3, 3357-3364. https://doi.org/10.1021/ acsomega.7b02037.

Prata, J.C., da Costa, J.P., Lopes, I., Duarte, A.C., Rocha-Santos, T., 2020. Environmental exposure to microplastics: an overview on possible human health effects. Sci. Total Environ. 702, 134455. https://doi.org/10.1016/j.scitotenv.2019.134455.

Ragusa, A., Svelato, A., Santacroce, C., Catalano, P., Notarstefano, V., Carnevali, O., Papa, F., Rongioletti, M.C.A., Baiocco, F., Draghi, S., D’Amore, E., Rinaldo, D., Matta, M., Giorgini, E., 2021. Plasticenta: first evidence of microplastics in human placenta. Environ. Int. 146, 106274. https://doi.org/10.1016/j.envint.2020.106274.

Rius-Ayra, O., Llorca-Isern, N., 2021. A robust and anticorrosion non-fluorinated superhydrophobic aluminium surface for microplastic removal. Sci. Total Environ. 760, 144090. https://doi.org/10.1016/j.scitotenv.2020.144090.

Rius-Ayra, O., Bouhnouf-Riahi, O., LLorca-Isern, N., 2020. Superhydrophobic and sustainable nanostructured powdered Iron for the efficient separation of oil-in-water emulsions and the capture of microplastics. ACS Appl. Mater. Interfaces 12 , 45629-45640. https://doi.org/10.1021/acsami.0c13876.

Saleema, N., Sarkar, D.K., Paynter, R.W., Chen, X.G., 2010. Superhydrophobic aluminum alloy surfaces by a novel one-step process. ACS Appl. Mater. Interfaces 2 , 2500-2502. https://doi.org/10.1021/am100563u.

Song, J., Xu, W., Lu, Y., 2012. One-step electrochemical machining of superhydrophobic surfaces on aluminum substrates. J. Mater. Sci. 47, 162-168. https://doi.org/ 10.1007/s10853-011-5783-2.

Song, J., Li, Y., Xu, W., Liu, H., Lu, Y., 2019. Inexpensive and non-fluorinated superhydrophobic concrete coating for anti-icing and anti-corrosion. J. Colloid Interface Sci. 541, 86-92. https://doi.org/10.1016/j.jcis.2019.01.014.

$\mathrm{Su}, \mathrm{B}$. , Tian, Y., Jiang, L., 2016. Bioinspired interfaces with superwettability: from materials to chemistry. J. Am. Chem. Soc. 138, 1727-1748. https://doi.org/ 10.1021/jacs.5b12728.

Talvitie, J., Mikola, A., Koistinen, A., Setälä, O., 2017. Solutions to microplastic pollution - removal of microplastics from wastewater effluent with advanced wastewater treatment technologies. Water Res. 123, 401-407. https://doi.org/10.1016/j. watres.2017.07.005

Teles, M., Balasch, J.C., Oliveira, M., Sardans, J., Peñuelas, J., 2020. Insights into nanoplastics effects on human health. Sci. Bull. 65, 1966-1969. https://doi.org/ 10.1016/j.scib.2020.08.003.

Vazirinasab, E., Jafari, R., Momen, G., 2018. Application of superhydrophobic coatings as a corrosion barrier: a review. Surf. Coat. Technol. 341, 40-56. https://doi.org/ 10.1016/j.surfcoat.2017.11.053.

Vengatesh, P., Kulandainathan, M.A., 2015. Hierarchically ordered self-lubricating superhydrophobic anodized aluminum surfaces with enhanced corrosion resistance. ACS Appl. Mater. Interfaces 7, 1516-1526. https://doi.org/10.1021/am506568v.

Wang, J., Wang, H., Yue, D., 2020a. Insights into mechanism of hypochlorite-induced functionalization of polymers toward separating BFR-containing components from microplastics. ACS Appl. Mater. Interfaces 12, 36755-36767. https://doi.org/ 10.1021/acsami.0c09586.
Wang, J., Yue, D., Wang, H., 2021. In situ Fe3O4 nanoparticles coating of polymers for separating hazardous PVC from microplastic mixtures. Chem. Eng. J. 407, 127170. https://doi.org/10.1016/j.cej.2020.127170.

Wang, L., Kaeppler, A., Fischer, D., Simmchen, J., 2019. Photocatalytic TiO 2 micromotors for removal of microplastics and suspended matter. ACS Appl. Mater. Interfaces 11, 32937-32944. https://doi.org/10.1021/acsami.9b06128.

Wang, R., Zhang, L., Chen, B., Zhu, X., 2020b. Low-pressure driven electrospun membrane with tuned surface charge for efficient removal of polystyrene nanoplastics from water. J. Membr. Sci. 614, 118470. https://doi.org/10.1016/j. memsci.2020.118470.

Wang, Z., Jiang, X., Cheng, X., Lau, C.H., Shao, L., 2015. Mussel-inspired hybrid coatings that transform membrane hydrophobicity into high hydrophilicity and underwater superoleophobicity for oil-in-water emulsion separation. ACS Appl. Mater. Interfaces 7, 9534-9545. https://doi.org/10.1021/acsami.5b00894.

Wu, R., Liang, S., Pan, A., Yuan, Z., Tang, Y., Tan, X., Guan, D., Yu, Y., 2012. Fabrication of nano-structured super-hydrophobic film on aluminum by controllable immersing method. Appl. Surf. Sci. 258, 5933-5937. https://doi.org/10.1016/j. apsusc.2011.10.029.

WWAP (United Nations World Water Assessment Programme), 2017. The United Nations World Water Development Report 2017. The Untapped Resource. UNESCO, Paris, Wastewater.

Xu, S., Ma, J., Ji, R., Pan, K., Miao, A.-J., 2020. Microplastics in aquatic environments: occurrence, accumulation, and biological effects. Sci. Total Environ. 703, 134699. https://doi.org/10.1016/j.scitotenv.2019.134699.

Yang, J., Chen, Y., Xu, P., Li, Y., Jia, X., Song, H., 2019. Fabrication of compressible and underwater superoleophobic carbon/g-C3N4 aerogel for wastewater purification. Mater. Lett. 254, 210-213. https://doi.org/10.1016/j.matlet.2019.07.069.

Zhang, B., Xu, W., Zhu, Q., Li, Y., Hou, B., 2018. Ultrafast one step construction of nonfluorinated superhydrophobic aluminum surfaces with remarkable improvement of corrosion resistance and anti-contamination. J. Colloid Interface Sci. 532, 201-209. https://doi.org/10.1016/j.jcis.2018.07.136.

Zhang, M., Yang, J., Kang, Z., Wu, X., Tang, L., Qiang, Z., Zhang, D., Pan, X., 2021. Removal of micron-scale microplastic particles from different waters with efficient tool of surface-functionalized microbubbles. J. Hazard. Mater. 404, 124095. https:// doi.org/10.1016/j.jhazmat.2020.124095.

Zhang, Y., Kang, S., Allen, S., Allen, D., Gao, T., Sillanpää, M., 2020. Atmospheric microplastics: a review on current status and perspectives. Earth-Science Rev. 203, 103118. https://doi.org/10.1016/j.earscirev.2020.103118.

Zhou, R., Lu, G., Yan, Z., Jiang, R., Bao, X., Lu, P., 2020. A review of the influences of microplastics on toxicity and transgenerational effects of pharmaceutical and personal care products in aquatic environment. Sci. Total Environ. 732, 139222. https://doi.org/10.1016/j.scitotenv.2020.139222.

Ziajahromi, S., Neale, P.A., Leusch, F.D.L., 2016. Wastewater treatment plant effluent as a source of microplastics: review of the fate, chemical interactions and potential risks to aquatic organisms. Water Sci. Technol. 74, 2253-2269. https://doi.org/10.2166/ wst.2016.414. 